\title{
Factors associated with low quality of life in schizophrenia
}

\author{
Fatores associados com a baixa \\ qualidade de vida na esquizofrenia
}

\author{
1 Departamento de Medicina \\ Preventiva e Social, \\ Universidade Federal \\ de Minas Gerais, \\ Belo Horizonte, Brasil. \\ 2 Grupo de Pesquisa \\ em Epidemiologia, \\ Universidade Federal \\ de Minas Gerais, \\ Belo Horizonte, Brasil. \\ 3 Departamento de \\ Psicologia, Universidade \\ Federal de São João del Rei, \\ São João del Rei, Brasil. \\ 4 Departamento de \\ Estatística, Universidade \\ Federal de Minas Gerais, \\ Belo Horizonte, Brasil. \\ Correspondence \\ C. S. Cardoso \\ Grupo de Pesquisas em \\ Epidemiologia, Faculdade \\ de Medicina, Universidade \\ Federal de Minas Gerais. \\ Av. Alfredo Balena 190, \\ sala 8.013, Belo Horizonte, $M G$ \\ 30130-100, Brasil. \\ clareci@medicina.ufmg.br \\ clareci@bol.com.br
}

\begin{abstract}
Interest in quality of life in mental health care has been stimulated by the deinstitutionalization of psychiatric patients as well as a parallel interest in understanding the scope of their daily lives. This study aims to investigate the sociodemographic and clinical variables related to low quality of life, using a cross-sectional design to evaluate quality of life by means of the QLSBR scale. We interviewed a sample of 123 outpatients from a reference mental health center in Divinópolis, Minas Gerais State, Brazil, clinically diagnosed with schizophrenia. Univariate and multivariate logistic regression analyses were carried out. The results showed that low quality of life is associated with one or more of the following: male gender, single marital status, low income plus low schooling, use of three or more prescribed psychoactive drugs, psychomotor agitation during the interview, and current follow-up care. The study identifies plausible indicators for the attention and care needed to improve psychiatric patient treatment.
\end{abstract}

Schizophrenia; Quality of Life; Mental Health
Clareci Silva Cardoso 1,2

Waleska Teixeira Caiaffa 1,2 Marina Bandeira ${ }^{3}$ Arminda Lucia Siqueira 4 Mery Natali Silva Abreu 2,4 José Otávio Penido Fonseca 1,2

\section{Introduction}

Psychiatric care in Brazil was based mainly on hospitalization until the 1980s, when a change in mental health policy proposed a shift to alternative, community-based services 1 . Deinstitutionalization, now a worldwide process which began more than five decades ago in other countries, has demonstrated significant gains for psychiatric care and treatment. Along with its advances, this process has received intense criticism based on an alleged lack of adequate care, in addition to patient vulnerability and social isolation. Precarious living conditions, in addition to difficulties in access, availability, and quality of services have been identified as the principal factors accounting for difficulties in social integration of individuals with mental distress 2,3 .

The results of psychiatric rehabilitation programs combined with the evolution of antipsychotic drugs have made in-community treatment possible for patients with schizophrenia, thus drastically reducing hospital admissions. Evaluation studies on services for these patients focus more on improvement in quality of life than the cure process 4 . Likewise, other studies identify quality of life as an important (if not the most important) measure of the impact of schizophrenia and its respective treatment 5,6. Such evaluation has been used in various studies and has proven to be an essential tool for constructing mental health indicators 6,7,8,9,10,11,12,13. 
There is no single and universal concept of quality of life. Although the World Health Organization's definition focuses on the patients' subjective evaluation of different life domains 14 , recent studies indicate that both objective and subjective indicators are necessary to conceptualize quality of life. Such studies view this concept as imbued with the social and cultural notion of health and disease, thus justifying the need for inter-cultural studies 15 , whether in the validation of measurement instruments 16,17 or in the investigation of factors associated with quality of life 2,15.

In the Brazilian context, no studies have been found thus far on factors associated with low quality of life in patients with schizophrenia, a gap that could be attributed to the lack of an evaluation instrument validated in the country.

Based on a recent validation study for a quality of life scale for Brazil 16,17, the current study proposes to investigate the clinical and sociodemographic factors associated with low quality of life measured by the QLS-BR scale in patients with diagnosed schizophrenia.

\section{Method}

\section{Sample}

The sample consists of psychiatric patients recruited from a Mental Health Reference Service (SERSAM). Eligibility criteria for the sample were: confirmed diagnosis of schizophrenia (ICD-10) 18 with minimum evolution of one year; patient deinstitutionalized; age range 18 to 55 years; absence of neurological disorder, mental retardation, or history of substance addiction; and stable clinical condition in the three weeks prior to the data collection, as indicated by absence of hospitalization and information from family member and health services staff.

From February 1997 to August 2000 the service identified a total of 230 eligible patient files. Fifty-four patients (23.5\%) failed to appear for the recruitment, 34 (14.8\%) were not located at the patient file address, and $2(0.9 \%)$ had died. Nineteen patients $(8.3 \%)$ failed to meet the inclusion criteria at the time of the interview and were either hospitalized or in crisis.

The study thus included a total of 123 patients. Calculation of the sample's power was based on the final logistic regression model 19, according to the following procedures: (1) choice of the variable with the greatest clinical rele- vance; (2) estimation of the probability of occurrence of the event in exposed and unexposed patients in the category, using the sample distribution and odds ratio from the final model; (3) estimation of the correlation between the model's principal variable and other variables; and (4) final calculation of the power based on the estimated probabilities in steps 2 and 3 , using a significance level of 0.05 . The analysis indicated that for the total scale and specific domains, the sample's detection power varied from 77.0 to $99.0 \%$.

\section{Study area}

Participants were recruited from the SERSAM, part of the Unified National Health System (SUS) in Divinópolis, a city located in centralwestern Minas Gerais State with a predominantly urban population of 183,708 (Instituto Brasileiro de Geografia e Estatística. http://www. ibge.gov.br/cidadesat/default.php, accessed on 17/Oct/2003). SERSAM-Divinópolis, founded in February 1997, is a reference service for the municipality and region, offering outpatient, emergency, and day-hospital care and rehabilitation.

\section{Procedure}

A cross-sectional study was conducted using the QLS-BR and a questionnaire containing the patients' clinical and socio-demographic data.

Patients were invited to participate in the study, systematically (up to three times), by telegram or telephone call, requesting that they appear at the clinic. After signing an informed consent form, each patient participated in a semi-structured interview conducted by three previously trained interviewers.

All the ethical principles contained in the Declaration of Helsinki were observed, and the research project was approved by the Institutional Review Board/ Research Ethics Committee of the Federal University in Minas Gerais, file number $035 / 01$.

\section{Description of the QLS-BR scale}

This instrument was developed specifically for patients with schizophrenia 20 and was developed in keeping with the deficit syndrome, aimed at evaluating the most insidious aspects of the disease. It was adapted for Brazil using an internationally recommended methodology 
16 and presented adequate validity and reliability 17. The study of the qualities of the measures, presented in detail in another publication, included inter-evaluator reliability, testretest, patient response reliability, diagnostic reliability, internal consistency, and construct validity 17 .

The dimensional structure of the QLS-BR scale has a total of 21 items distributed among the following three factors or domains: (1) social domain, (2) occupational domain, and (3) intrapsychic foundations and interpersonal relations domain. The items include information on the patient's functioning during the three weeks prior to the interview, approaching specific aspects in the patient's life such as family relationship, social isolation, occupational functioning and satisfaction, and motivation, among others. Each question is evaluated by the interviewer during the patient interview, and the interviewer attributes a standard score to each question after obtaining the relevant information, according to the patient's answers, by means of a 7 -point grading scale. Scores of 5 and 6 reflect unaltered quality of life, 2 to 4 show moderately compromised quality of life, and scores 0 and 1 indicate a severely compromised quality of life 17.

\section{Data analysis}

A logistic regression model was used to evaluate the association between the scores from the QLS-BR scale and the patients' clinical and socio-demographic characteristics. The response variable was the quality of life score measured by the QLS-BR, coded in two categories (case, with score $<2$, and reference, with $\geq 2$ ). The coding choice was due to the fact that there were few patients in the third QLS-BR category (scores 5 and 6). A separate analysis was performed for the total scale and each specific domain. The explanatory variables were socio-demographic and clinical.

The backward procedure was used for selection of covariables. This criterion consisted of initially selecting all the variables which in the univariate analysis showed a $\mathrm{p}$-value $\leq 0.25$ 19 , with the exception of gender, age, and time of psychiatric treatment, which entered into model regardless of the respective p-value, since they have been described in the literature as important predictors of quality of life 21,22,23. A logistic model was adjusted, eliminating the variables individually. The criterion for the variables to remain in the final model was a p-value $\leq 0.05$. The SPSS 11.5 statistical software was used for the analysis.

\section{Results}

\section{Patient characteristics}

Mean patient age was 37.5 years, with the majority male $(60.2 \%)$ and with less than three years of schooling (75.6\%). Nearly half lived with their parents $(48.8 \%)$. A high percentage was single (74.8\%), with a family income of one to two times the prevailing minimum wage, or approximately US $\$ 100$ to US\$200 per month (54.1\%), with five or more people in the household $(68.3 \%)$. The majority had a diagnosis of paranoid schizophrenia (87.8\%), with duration of the disease greater than six years $(61.8 \%)$. More than half of the patients were taking three or more drugs (56.9\%) and were in outpatient treatment $(82.1 \%)$. Some $27.0 \%$ reported never having been hospitalized. The vast majority appeared calm during the interview (95.1\%), and a small proportion of the patients presented delusional activity (6.5\%). Mean duration of the interview was one hour.

\section{Univariate logistic regression analysis}

For the total scale and the 21 items, highlighted in bold print in Table 1, all the socio-demographic variables met the univariate criterion ( $p \leq 0.25$ ) except for the number of members in the household. Of the clinical variables, four met the same criterion: diagnosis $(p=0.17$ ), treatment time $(\mathrm{p}=0.22)$, patient status at interview ( $p=0.19$ ), and presence of delusional activity $(\mathrm{p}=0.04)$.

For the specific domains, as highlighted in bold print in Table 2, some variables met the univariate criterion for the three domains, such as marital status, whom the individual lives with, hospitalization time $\geq 6$ months, outpatient treatment, and delusional activity. Other variables were only significant for one specific domain, such as schooling ( $p=0.02)$, psychiatric treatment time $\geq 6$ years $(p=0.07)$, and duration of interview ( $p=0.20$ ) in the social domain. Likewise, the variables age $(p<0.01)$ and diagnosis $(\mathrm{p}=0.20)$ were only significant for the occupational domain. For the domain related to intrapsychic and interpersonal functions, all the variables that were significant in this context had already met the univariate criterion for another domain.

\section{Multivariate logistic regression analysis}

Table 3 shows the variables associated with low quality of life score in the final model. The model included all variables that met the uni- 
Distribution of frequencies and results in the univariate logistic regression analysis for low global quality of life score* in the QLS-BR scale $(n=123)$.

\begin{tabular}{|c|c|c|c|c|}
\hline Variables & $\begin{array}{c}\text { Score }<2 \\
(n=45) \\
\%\end{array}$ & $\begin{array}{c}\text { Score } \geq 2 \\
(n=78) \\
\%\end{array}$ & OR & $95 \mathrm{Cl} \%$ \\
\hline \multicolumn{5}{|l|}{ Socio-demographic } \\
\hline \multicolumn{5}{|l|}{ Gender } \\
\hline Female & 24.5 & 75.5 & 1.00 & \\
\hline Male & 44.6 & 55.4 & 2.48 & $1.19-5.50$ \\
\hline \multicolumn{5}{|l|}{ Age (years) } \\
\hline$\geq 38$ & 30.0 & 70.0 & 1.00 & \\
\hline$<38$ & 42.8 & 57.2 & 1.75 & $0.83-3.68$ \\
\hline \multicolumn{5}{|l|}{ Schooling (years) } \\
\hline$\geq 4$ & 26.7 & 73.3 & 1.00 & \\
\hline$<4$ & 39.8 & 60.2 & 1.82 & $0.73-4.51$ \\
\hline \multicolumn{5}{|l|}{ Marital status ${ }^{\star \star}$} \\
\hline Married & 19.4 & 80.6 & 1.00 & \\
\hline Single & 42.4 & 57.6 & 3.07 & $1.15-8.19$ \\
\hline \multicolumn{5}{|c|}{ Family income (times minimum wage) } \\
\hline$\geq 3$ & 28.6 & 71.6 & 1.00 & \\
\hline$<3$ & 42.4 & 57.6 & 1.84 & $0.86-3.93$ \\
\hline \multicolumn{5}{|c|}{ Number of persons in household } \\
\hline$\geq 5$ & 30.8 & 69.2 & 1.00 & \\
\hline$<5$ & 39.3 & 60.7 & 1.46 & $0.65-3.27$ \\
\hline \multicolumn{5}{|l|}{ Lives with whom** } \\
\hline Other & 25.4 & 74.6 & 1.00 & \\
\hline Parents & 48.3 & 51.6 & 2.75 & $1.28-5.88$ \\
\hline \multicolumn{5}{|l|}{ Clinical } \\
\hline \multicolumn{5}{|l|}{ Diagnosis (ICD-10) 18} \\
\hline Other subtypes & 20.0 & 80.0 & 1.00 & \\
\hline Paranoid schizophrenia & 38.9 & 61.1 & 2.54 & $0.68-9.56$ \\
\hline \multicolumn{5}{|c|}{ Psychiatric treatment time (years) ${ }^{\star \star}$} \\
\hline$\leq 5$ & 29.8 & 70.2 & 1.00 & \\
\hline$\geq 6$ & 40.8 & 59.2 & 1.62 & $0.75-3.52$ \\
\hline \multicolumn{5}{|c|}{ Total psychiatric hospitalization time $e^{\star \star}$} \\
\hline Never hospitalized & 36.4 & 63.6 & 1.00 & \\
\hline$\leq 6$ months & 32.8 & 67.2 & 0.85 & $0.35-2.07$ \\
\hline$>6$ months & 44.8 & 55.1 & 1.42 & $0.51-3.94$ \\
\hline \multicolumn{5}{|l|}{ Current medical treatment } \\
\hline Other ${ }^{\star \star \star}$ & 27.3 & 72.7 & 1.00 & \\
\hline Outpatient treatment\# & 38.6 & 61.4 & 1.68 & $0.60-4.65$ \\
\hline \multicolumn{5}{|l|}{ Number of medications } \\
\hline $0-2$ & 39.6 & 60.4 & 1.00 & \\
\hline$\geq 3$ & 34.3 & 65.7 & 0.79 & $0.38-1.66$ \\
\hline \multicolumn{5}{|c|}{ Patient status during interview } \\
\hline Calm & 34.0 & 66.0 & 1.00 & \\
\hline Agitated & 50.0 & 50.0 & 1.94 & $0.74-5.14$ \\
\hline \multicolumn{5}{|l|}{ Interruption of interview } \\
\hline Yes & 33.3 & 66.7 & 1.00 & \\
\hline No & 36.8 & 63.2 & 1.16 & $0.20-6.61$ \\
\hline \multicolumn{5}{|l|}{ Delusional activity } \\
\hline No & 33.9 & 66.1 & 1.00 & \\
\hline Yes & 75.0 & 25.0 & 5.85 & $1.13-30.33$ \\
\hline \multicolumn{5}{|l|}{ Total interview time (hours) } \\
\hline 1 & 36.0 & 64.0 & 1.00 & \\
\hline More than 1 & 39.1 & 60.9 & 1.15 & $0.45-2.90$ \\
\hline
\end{tabular}

* Global score: includes all 21 items from the QLS-BR scale;

** Variables presenting colinearity;

*** Category includes the following items: no current treatment, use of medication without follow-up, follow-up but without medication, and irregular use of medication:

\# Category includes: periodic consultations and regular use of medication. 
Results of univariate logistic regression analysis for low quality of life in the three domains of the QLS-BR scale ( $n=123$ ).

\begin{tabular}{|c|c|c|c|c|c|c|}
\hline \multirow[t]{2}{*}{ Variables } & \multicolumn{2}{|c|}{ Social domain* } & \multicolumn{2}{|c|}{ Occupational domain ${ }^{\star \star}$} & \multicolumn{2}{|c|}{$\begin{array}{l}\text { Intrapsychic functions and } \\
\text { interpersonal relations }\end{array}$} \\
\hline & OR & $95 \% \mathrm{Cl}$ & OR & $95 \% \mathrm{Cl}$ & OR & $95 \% \mathrm{Cl}$ \\
\hline \multicolumn{7}{|l|}{ Socio-demographic } \\
\hline $\begin{array}{l}\text { Gender } \\
\text { Male }\end{array}$ & 1.96 & $0.94-4.99$ & 4.12 & $1.89-8.94$ & 1.23 & $0.57-2.66$ \\
\hline $\begin{array}{l}\text { Age (years) } \\
\quad<38\end{array}$ & 1.18 & $0.58-2.39$ & 2.62 & $1.27-5.44$ & 1.16 & $0.55-2.25$ \\
\hline $\begin{array}{l}\text { Schooling (years) } \\
\quad<4\end{array}$ & 2.83 & $1.17-6.84$ & 1.60 & $0.69-3.69$ & 1.51 & $0.61-3.77$ \\
\hline $\begin{array}{l}\text { Marital status } \\
\text { Single }\end{array}$ & 1.73 & $0.75-3.96$ & 5.92 & $2.22-15.82$ & 2.56 & $0.95-6.85$ \\
\hline $\begin{array}{l}\text { Monthly income (times mi } \\
<3\end{array}$ & 1.50 & $0.73-3.08$ & 1.01 & $0.50-2.06$ & 1.23 & $0.57-2.63$ \\
\hline $\begin{array}{l}\text { Number of persons in hou } \\
<5\end{array}$ & 0.86 & $0.40-1.83$ & 0.74 & $0.35-1.59$ & 1.41 & $0.62-3.24$ \\
\hline $\begin{array}{l}\text { Lives with whom } \\
\text { Parents }\end{array}$ & 1.63 & $0.80-3.32$ & 5.83 & $2.68-12.69$ & 1.80 & $0.84-3.85$ \\
\hline Clinical & & & & & & \\
\hline $\begin{array}{l}\text { Diagnosis (ICD-10) } 18 \\
\quad \text { Paranoid schizophrenia }\end{array}$ & 1.01 & $0.37-3.25$ & 2.07 & $0.66-6.48$ & 0.72 & $0.24-2.18$ \\
\hline $\begin{array}{l}\text { Psychiatric treatment time } \\
\geq 6\end{array}$ & 1.99 & $0.95-4.18$ & 1.14 & $0.55-2.35$ & 0.95 & $0.44-2.05$ \\
\hline $\begin{array}{l}\text { Total psychiatric hospitaliz } \\
>6\end{array}$ & 1.54 & $0.56-4.25$ & 0.97 & $0.36-2.66$ & 2.21 & $0.74-6.54$ \\
\hline $\begin{array}{l}\text { Current treatment } \\
\text { Outpatient }\end{array}$ & 3.06 & $1.11-8.47$ & 2.37 & $0.89-6.29$ & 1.88 & $0.64-5.53$ \\
\hline $\begin{array}{l}\text { Number of medications } \\
\geq 3\end{array}$ & 0.86 & $0.80-5.58$ & 0.50 & $0.18-1.25$ & 2.05 & $0.85-9.03$ \\
\hline $\begin{array}{l}\text { Patient status during inter } \\
\text { Agitated }\end{array}$ & 1.06 & $0.41-2.76$ & 2.89 & $1.03-8.12$ & 3.83 & $1.42-10.32$ \\
\hline $\begin{array}{l}\text { Interview interrupted } \\
\text { No }\end{array}$ & 0.95 & $0.18-4.90$ & 0.95 & $0.18-4.90$ & 0.48 & $0.09-2.50$ \\
\hline $\begin{array}{l}\text { Delusional activity } \\
\text { Yes }\end{array}$ & 3.38 & $0.65-17.44$ & 8.18 & $0.98-68-54$ & 3.66 & $0.83-16.14$ \\
\hline $\begin{array}{l}\text { Total interview time (hours } \\
\text { More than } 1\end{array}$ & 1.83 & $0.72-4.60$ & 0.62 & $0.24-1.56$ & 1.37 & $0.53-3.49$ \\
\hline
\end{tabular}

* Items in the factor: relationships with household, intimate relationships, active friendships, social activity,

social network, social initiatives, social withdrawal (score $<2: n=60$; score $\geq 2: n=63$ );

** Items in the factor: occupational functioning, level of accomplishment, underemployment,

occupational satisfaction, time utilization (score $<2$ : $n=60$; score $\geq 2: n=63$ );

$\star \star \star$ Items in the factor: affective-sexual relations, sense of purpose in life, curiosity, common objects,

common activities, empathy, interaction with interview (score $<2: n=41$; score $\geq 2: n=82$ ).

variate criterion, together with age, gender, and treatment time. Since the variable "whom you live with" showed high colinearity with "marital status", we chose to maintain only marital status. A similar problem was found between "total hospitalization time" and "total psychiatric treatment time", so we chose to maintain the latter. We also excluded the variable "presence of delusional activity", because it included a small number of patients $(n=8)$ and therefore generated a wide confidence interval, re- sulting in low precision in the estimated odds ratio.

For the global quality of life score, that is, all 21 items, men showed 2.5 greater odds of being in the low quality of life range as compared to women, while single marital status was three times more likely to be associated with low quality of life (OR $=3.04$ ) as compared to married. Socioeconomic status, although borderline $(\mathrm{OR}=2.20 ; 95 \% \mathrm{CI}: 0.98-4.90)$, indicated that family income less than two times the 
Results of multivariate logistic regression for low quality of life on total score and the three factors in the QLS-BR scale: odds ratio estimate, $95 \%$ confidence interval, and $p$-value $(n=123)$.

\begin{tabular}{|c|c|c|c|c|c|c|c|c|}
\hline \multirow[t]{2}{*}{ Explanatory variables* } & \multicolumn{2}{|c|}{ Total scale (21 items) } & \multicolumn{2}{|c|}{ Social domain ${ }^{\star \star}$} & \multicolumn{2}{|c|}{ Occupational domain ${ }^{\star \star \star}$} & \multicolumn{2}{|c|}{$\begin{array}{l}\text { Intrapsychic functions and } \\
\text { interpersonal relations\# }\end{array}$} \\
\hline & OR & $95 \% \mathrm{Cl}$ & OR & $95 \% \mathrm{Cl}$ & OR & $95 \% \mathrm{Cl}$ & OR & $95 \% \mathrm{Cl}$ \\
\hline \multicolumn{9}{|l|}{ Socio-demographic } \\
\hline \multicolumn{9}{|l|}{ Gender } \\
\hline Male & 2.52 & $1.09-5.78$ & - & - & 4.18 & $1.83-9.52$ & - & - \\
\hline \multicolumn{9}{|l|}{ Marital status } \\
\hline Single & 3.04 & $1.10-8.40$ & - & - & 6.02 & $2.16-16.95$ & 2.83 & $1.01-8.00$ \\
\hline \multicolumn{9}{|l|}{ Schooling (years) } \\
\hline$<4$ & - & - & 2.86 & $1.17-7.04$ & - & - & - & - \\
\hline \multicolumn{9}{|l|}{ Income } \\
\hline$<3$ times minimum wage & 2.20 & $0.98-4.90$ & - & - & - & - & - & - \\
\hline \multicolumn{9}{|l|}{ Clinical } \\
\hline \multicolumn{9}{|l|}{ Number of medications } \\
\hline$\geq 3$ & - & - & - & - & - & - & 2.43 & $1.05-5.64$ \\
\hline \multicolumn{9}{|l|}{ Current treatment } \\
\hline Outpatient & - & - & 3.11 & $1.10-8.77$ & - & - & - & - \\
\hline \multicolumn{9}{|l|}{ Patient status } \\
\hline Agitated & - & - & - & - & - & - & 3.58 & $1.28-10.00$ \\
\hline p-value\#\# & 0.90 & 0.98 & 0.75 & 0.88 & & & & \\
\hline
\end{tabular}

* All variables entered into the model simultaneously;

** Items in the domain: relationships with household, intimate relationships, active friendships, social activity, social network, social initiative, social withdrawal:

${ }_{\star \star *}$ Items in the domain: occupational functioning, level of accomplishment, underemployment, occupational satisfaction, time utilization; \# Items in the domain: affective-sexual relations, sense of purpose in life, curiosity, commonplaces objects, commonplaces activities, empathy, interaction with interview;

\#\# Hosmer \& Lemeshow goodness-of-fit test 19

minimum wage (i.e. less than US $\$ 200 /$ month) doubled the odds of the patient presenting low quality of life, as compared to individuals with higher incomes. No clinical variable was associated with total quality of life.

For quality of life related specifically to the social network domain, only two variables were independently associated in the final model. Low schooling showed an odds ratio of 2.9 for low quality of life as compared to higher schooling, while current outpatient treatment tripled the odds of low quality of life $(\mathrm{OR}=3.11)$ as compared to other types of treatment or no treatment.

For quality of life related to the occupational domain, males showed an OR of 4.0 for low quality of life as compared to females. Single marital status showed a six-fold odds of low quality of life in this domain as compared to married patients $(\mathrm{OR}=6.02)$.

In relation to quality of life in the intrapsychic and interpersonal domain, three variables were independently associated with low quality of life. Single marital status and using three or more psychoactive drugs more than dou- bled the odds of a worse score (odds ratios of 2.83 and 2.43, respectively). Meanwhile, patients who were agitated during the interview had 3.6 greater odds of having low quality of life in this domain as compared to the non-agitated group.

Of the variables included in the model, due to their clinical relevance, only gender remained in the final model. Age and total treatment time were not significant for low quality of life score in the adjusted model.

\section{Discussion}

According to this study, male gender, single marital status, and low schooling and income were important socio-demographic variables associated with low quality of life in patients with schizophrenia. In addition, three clinical variables were also associated with low quality of life: current use of three or more psychoactive drugs, current outpatient treatment, and psychomotor agitation during the interview. Several variables were also associated with to- 
tal low quality of life and various specific domains.

These results confirm that in schizophrenia, although the different areas are interrelated, the dysfunctions can operate independently and can thus have different predictive factors 24 . Along with these findings, other studies have suggested that the global de quality of life score has proven inconsistent with the score in specific areas 25 , thus justifying a separate analysis of the factors associated with low quality of life in the specific domains and global scale. Other studies indicate that a better predictive model for quality of life is obtained when it combines socio-demographic and clinical characteristics 24 , as well as objective and subjective indicators 26 .

The results of the associations found in this study appear to be consistent with those in the literature. Male gender is described as a predictor of low quality of life, and its importance has been identified in various studies 8,15,23. Among women, disease course and living situation are seen as more favorable, and women thus prove to be more satisfied than men 24 .

The significant presence of males as compared to females in the occupational domain and global scale indicated a two- to fourfold greater odds of men presenting low quality of life, and may suggest greater female involvement in (and/or commitment to) household responsibilities, unlike men, who stay at home with little or no responsibility because of their illness. In fact, a Brazilian study on differences between genders in schizophrenia identified better performance by women in the occupational domain, even when housework was excluded from the analysis. Added to this is the fact that men show earlier onset of the disease, greater disability in social functioning, greater inactivity and social isolation, more inertia, and a lower proportion of married individuals than women 23 . In relation to the lower proportion of married men, the current study confirmed this information descriptively, with a higher proportion of married women $(30.6 \%)$ as compared to married men $(21.6 \%)$.

In this context, being single appears to be an important variable for low quality of life, and there are reports that men with a diagnosis of schizophrenia show a higher probability of remaining single 23 . In the current study, this variable was associated with low quality of life both on the global scale and in the occupational and intrapsychic domains and in interpersonal relations, even after adjusting for gender.

Marital status was also identified as one of the best predictors of evolution in schizophre- nia. Being married and having adequate premorbid psychosocial adaptation are related to a more favorable prognosis. It has been described that the risk of hospitalization in single patients increases with age. However, this effect is not observed in married patients 24 .

The fact that single marital status is associated with low quality of life in the intrapsychic domain and in interpersonal relations may suggest that affective-sexual relations are precarious in this group of patients. This domain includes items related to sexual activity, sense of purpose in life, curiosity, empathy, and interaction. In this context, single patients with a diagnosis of schizophrenia almost never have sexual involvement or even affective relations with other individuals. This was confirmed by the QLS-BR score on the item affective-sexual relations, where the median was 1.00 for both men and women, indicating an extremely impoverished quality of life for the item at issue. In the total scale and occupational domain, on the other hand, single marital status carried a connotation of social and occupational integration, including by the nature of the items evaluated.

Low schooling was only significant for the social network domain $(\mathrm{OR}=2.86)$. Other studies have also found an association between low schooling in schizophrenia and quality of life, whereby better educational level was associated with better psychopathological status in the disease evolution 27 , better adjustment in social functioning 21 , and greater satisfaction with life 28. However, the literature diverges as to the relationship between quality of life and low schooling in schizophrenia. In underdeveloped countries, patients with higher educational levels appear to have a worse evolution in the disease, due to the higher social demands and expectations as compared to patients with low schooling. According to a Brazilian study on social adjustment in schizophrenia, an area closely related to quality of life, low schooling was predictive of poor social functioning 21 , as in the current study, in which it remained associated with low quality of life in the social domain.

It is possible that since patients enrolled in the Divinópolis program had not acquired minimum schooling, they may have presented limited skills for coping with the social demands and expectations of a developing city, thus reflecting a greater probability of reporting low quality of life on items requiring social involvement and interaction. Other studies in Brazil have indicated that schooling is associated with health services-use patterns, behaviors, and the ability to understand educational and 
health messages 21,29, which may ultimately be associated with a definition of quality of life, whether high or low.

In the current study, income less than US $\$ 200 /$ month was only associated with low quality of life score in the global scale $(\mathrm{OR}=2.20)$. Individuals with income less than US\$300/ month showed twice the odds of having low quality of life. Quality of life evaluation has shown that psychiatric patients are less satisfied with their finances than with other domains 7,30, although other studies have found contradictory results relating objective life conditions and the subjective perception of such conditions. In other words, according to the patient's perception, a good living standard may not reflect good quality of life 31,32 .

The clinical variables related to the number of medications, current treatment, and patient's status during the interview were only significantly associated in two specific domains: social network and intrapsychic functions and interpersonal relations.

A proposed model for evaluating factors associated with quality of life in patients with a diagnosis of schizophrenia and on medication concluded that the increased variance in quality of life was explained by severity of symptoms (32.0\%) and the adverse effect of antipsychotic medication and patient's functional level (17.0\%) 33. Although we lack information on the drug classification and even adverse reactions, our findings appear to be consistent with those of the literature. The greater the number of medications used by the patient, the worse the quality of life in the intrapsychic domain, suggesting greater disease severity; approximately $60.0 \%$ of patients presenting delusional activity or psychomotor agitation during the interview were using three or more drugs.

A bivariate analysis of the data showed a significant association between number of drugs and income, where most of the patients on three or more medications $(60.0 \%)$ had better family incomes. Since virtually all of the medications are available through the SUS, this association cannot be easily explained based on ease of acquiring the medication. One possibility is that individuals with higher family incomes could be more knowledgeable and/or have greater family involvement in their medication, which could even lead to use of more prescribed medications.

In this study, current outpatient treatment (outpatient consultation and regular use of medication) showed a three-fold increase in low quality of life. This result is backed by the literature, not by the type of treatment per se, but by the fact that the more severe patients (and thus those with low quality of life) use the mental health programs more frequently through outpatient follow-up, as compared to less severe patients. In fact, publications with literature reviews in this area in the last 15 years have shown similar trends, whereby patients with greater autonomy and less contact with mental health services perceived a better quality of life 26,34 .

Services utilization is a widely used variable in quality of life studies. One study showed that the greater the patients' autonomy, the less they use the service, suggesting an improved clinical condition 2 . Such results are similar to those of the current study, since the patients that were not under any kind of treatment and did not report use of medication presented better quality of life.

As expected, two clinical variables were associated with low quality of life in the intrapsychic and interpersonal relations domain: taking three or more medications $(\mathrm{OR}=2.43$ ) and psychomotor agitation during the interview $(\mathrm{OR}=2.43)$. Another important clinical variable was delusional activity during the interview, which was significant in the univariate analysis for low total quality of life score and for all the domains. In the multivariate model it generated imprecise measures due to the small number of patients, and we thus chose to remove it from the final model. This fact does not rule out its importance for low quality of life in patients, confirming what has been shown by various other studies on the importance of symptoms in the determination of quality of life $25,35,36$.

Comparison of international research results involving quality of life have shown important methodological limitations, especially in relation to patient comparability, cultural adequacy of the concept, difference in research instruments, and inclusion of different variables 15. This is the first study in Brazil aimed at investigating factors associated with low quality of life in schizophrenia. We used the multidimensional quality of life concept, including objective and subjective indicators, given that the QLS-BR scale includes both indicators, in addition to clinical and socio-demographic information.

The current study displays methodological limitations due to its cross-sectional design, in which the event and exposure are measured simultaneously. The study was planned to both guarantee and control the data quality by means of training and follow-up of interviewers and inter-evaluator and patient response 
reliability analyses, described in detail in another publication 17 , with the objective of offsetting the information bias. In addition, the possibility of the patient offering desired responses cannot be ruled out, which in this case would lead to possible underestimation of exposure and consequently underestimation of risk. In addition, caution should be exercised in extrapolating these results to other patients with schizophrenia, since this study included stable patients as an eligibility criterion, thus failing to analyze possibly more severe patients. The same caution should be exercised in analyzing the percentage of losses $(42.0 \%)$, which did not differ by gender, age, or diagnosis, although similar to other studies on this population 34 .

It is important to note that this was a comparative study in which QLS-BR was divided into only two categories (quality of life score $<2$ and $\geq 2$ ), due to the limited frequency of patients classified as having normal or unaltered quality of life, as represented by scores of 5 and 6 . Thus, the study involved proximity in the event classification, comparing two groups of patients with some degree of compromise. This procedure may have lead to an underestimation of the measure of association (odds ratio) and may represent a conservative way of interpreting the magnitude of association.

As for the data reliability, this and other studies have demonstrated that patients with schizophrenia may report quality of life with high reliability $17,23,37,38$, as long as the study is performed with appropriate methodology.

Finally, considering the above-mentioned limitations, the current study suggests that some objective indicators such as gender and mari- tal status could be functioning as markers for social integration, as indicated by the virtual absence of relational ties in the majority of these patients. Low schooling, which also plays an important role in the social integration process, can be better observed by mental health programs by using, for example, clearer and more objective health information, including training in the capacity to interact with the environment, in the sense of providing support for patients' goals and needs. Low income, as an indicator of worse quality of life, points to the need for effective implementation of the mental health policy in relation to financial assistance for individuals with mental disorders. This point has already advanced in Brazil through Ruling $n .10 .708$ of July 31, 2003, which regulates financial assistance for previously hospitalized patients with mental disorders.

Meanwhile, the clinical markers evidenced in this study could be the target for intervention by mental health programs, by truly listening to these patients and their families, taking into account that the areas most affected by the health service's work are the patient's interpersonal contacts and internal experiences, such as thoughts and emotions 26.

Given these results, the issue of quality of life in schizophrenia merits further investigation, considering that this study was not originally designed to test associations. In particular, occupational activity as analyzed from the perspective of differences between genders, observed in preliminary fashion in this study, merits further research.

An on-going evaluation of patients' quality of life can make a crucial contribution to the planning of psychiatric services for this clientele.

\section{Resumo}

O interesse na qualidade de vida na saúde mental foi estimulado pelo processo de desinstitucionalização dos pacientes psiquiátricos e um paralelo interesse em conhecer as dimensões de sua vida diária. Este estudo teve como objetivo investigar as variáveis sócio-demográficas e clínicas relacionadas com uma baixa qualidade de vida. Foi conduzido um estudo transversal para avaliação da qualidade de vida por meio da escala QLS-BR em uma amostra de 123 pacientes ambulatoriais com diagnóstico de esquizofrenia, recrutados do serviço de referência em saúde mental de Divinópolis, Minas Gerais, Brasil. Os dados foram analisados utilizando-se regressão logística multivariada.
Os resultados indicaram que um pior escore de qualidade de vida estava associado ao sexo masculino, ser solteiro, ter renda e escolaridade baixas, estar em uso de três ou mais medicamentos, ter apresentado agitação psicomotora na entrevista e estar fazendo acompanhamento ambulatorial. Esse estudo aponta indicadores plausíveis para a atenção e cuidado do portador de sofrimento mental.

Esquizofrenia; Qualidade de Vida; Saúde Mental 


\section{Contributors}

C. S. Cardoso drafted the project, coordinated the various work components, participated in the field work, and supervised the data entry, analysis, and consistency and the drafting of the paper. W. T. Caiaffa oriented the study from the design through the analysis. M. Bandeira supervised the quality of life component. J. O. P. Fonseca supervised the chronic non-communicable diseases component. A. L. Siqueira provided statistical assistance. M. N. S. Abreu aided in the data entry and analysis. All the authors participated in drafting the paper and approved the final version.

\section{Acknowledgements}

The authors thank the Minas Gerais State Research Foundation (FAPEMIG) for the funding (project CDS301/02) and the National Research Council (CNPq) and Coordinating Body for Training University Level Personnel (CAPES) for grants to the following researchers: Waleska Teixeira Caiaffa, Marina Bandeira, Mery Natali Silva Abreu, and Clareci Silva Cardoso. They also wish to thank the Epidemiology Research Group at the Federal University in Minas Gerais for the research support. Special acknowledgements go to the Mental Health Reference Service in Divinópolis, Minas Gerais (SERSAM-Divinópolis) and to all the patients and family members for their support.

\section{References}

1. Brasil. Lei n. 10.216. Dispõe sobre a proteção e os direitos das pessoas portadoras de transtornos mentais e redireciona o modelo assistencial em saúde mental. Diário Oficial da União 2002; 9 abr.

2. Mercier C, King S. A latent variable causal model of the quality of life and community tenure of psychotic patients. Acta Psychiatr Scand 1994; 89:72-7.

3. Bandeira M, Gelinas D, Lesage A. Desinstitucionalização: o programa de acompanhamento intensivo na comunidade. J Bras Psiquiatr 1998; 47:627-40.

4. Bachrach LL, Lamb HR. Conceptual issues in the evaluation of the deinstitutionalization movement. In: Staler GJ, Tash WR, editors. Innovative approaches to mental health evaluation. New York: Academic Press; 1982.

5. Goeree R. Evaluation of programs for the treatment of schizophrenia, part II: a review of selected programs in Canada. Ottawa: Health Canada Publications, Minister of Supply and Services; 1996.

6. Tempier R, Mercier C, Leouffre P, Caron J. Quality of life and social integration of severely mentally ill patients: a longitudinal study. J Psychiatry Neurosci 1997; 22:249-55.

7. Sullivan G, Wells KB, Leak B. Clinical factors associated with better quality of life in a seriously mentally ill population. Hosp Community Psychiatry 1992; 43:794-8.

8. Roder-Wanner UU, Priebe S. Schizophrenia and quality of life-sex-specific aspects. Fortschr Neurol Psychiatr 1995; 63:393-401.

9. Spiridonow K, Kasperek B, Meder J. Subjective quality of life in patients with chronic schizophrenia and in healthy persons. Psychiatr Pol 1998; 32:297-306.

10. Bengtsson-Tops A, Hansson L. Clinical and social needs of schizophrenic outpatients living in the community: the relationship between needs and subjective quality of life. Soc Psychiatry Psychiatr Epidemiol 1999; 34:513-8.

11. Hanson L, Middelboe T, Merinder L, Bjarnason O, Bengtsson-Tops A, Nilsson L, et al. Predictors of subjective quality of life in schizophrenic patients living in the community. A Nordic multicentre study. Int J Soc Psychiatry 1999; 45:247-58.

12. Angermeyer MC. Schizophrenia and the quality of life. Fortschr Neurol Psychiatr 2000; 68 Suppl $1: S 2-6$.

13. Kasckow JW, Twamley E, Mulchahey JJ, Carroll B, Sabai M, Strakowski SM, et al. Health-related quality of well-being in chronically hospitalized patients with schizophrenia, comparison with matched outpatients. Psychiatry Res 2001; 103:6978.

14. WHOQOL Group. The development of the WHO quality of life assessment instrument (the WHOQOL). In: Orley J, Kuyken W, editors. Quality of life assessment: international perspectives. Heilelberg: Springer-Verlag; 1994. p. 41-60.

15. Gaite L, Vásquez-Barquero JL, Bota C, Ballesteros J, Schene A, Welcher B, et al. Quality of life in patients with schizophrenia in five European coun- 
tries: the EPSILON study. Acta Psychiatr Scand 2002;105:283-92.

16. Cardoso CS, Bandeira M, Caiaffa WT, Fonseca JOP. Escala de qualidade de vida para pacientes com esquizofrenia - QLS-BR: adaptação transcultural para o Brasil. J Bras Psiquiatr 2002; 51:31-8.

17. Cardoso CS, Bandeira M, Caiaffa WT, Siqueira AL, Fonseca IK, Fonseca JOP. Qualidades psicométricas da escala de qualidade de vida para pacientes com esquizofrenia: escala QLS-BR. J Bras Psiquiatr 2003; 52:211-22.

18. Organização Mundial da Saúde. Classificação estatística internacional de doenças e problemas relacionados à saúde, 10a revisão. v. 1. São Paulo: Centro Colaborador da OMS para a Classificação de Doenças em Português; 1995.

19. Hosmer DW, Lemeshow S. Applied logistic regression. 2nd Ed. New York: John Wiley \& Sons; 2000.

20. Heinrichs DW, Hanlon TE, Carpenter WT. The quality of life scale: an instrument for rating the schizophrenic deficit syndrome. Schizophrenia Bulletin 1984; 10:388-98.

21. Menezes PR, Nascimento AF. Curso e prognóstico da esquizofrenia após hospitalização. In: Shirakawa I, Chaves AC, Mari JJ, organizadores. O desafio da esquizofrenia. São Paulo: Lemos Editorial; 1998. p. 67-83.

22. Chaves AC. Diferença entre os sexos na esquizofrenia. In: Shirakawa I, Chaves AC, Mari JJ, organizadores. O desafio da esquizofrenia. São Paulo: Lemos Editorial; 1998. p. 85-101.

23. Chaves AC, Mari JJ, Shirakwa I. Gênero, sintomas e desempenho social na esquizofrenia. In: Shirakawa I, Chaves AC, Mari JJ, organizadores. O desafio da esquizofrenia. São Paulo: Lemos Editorial; 1998. p. 103-17.

24. Strauss JS, Carpenter Jr. WT. The prognosis of schizophrenia: rationale for a multidimensional concept. Schizophr Bull 1978; 4:56-67.

25. Dickerson FB, Ringel NB, Parente F. Subjective quality of life in out-patients with schizophrenia: clinical utilization correlates. Acta Psychiatr Scand 1998; 98:124-7.

26. Skantze K. Subjective quality of life and standard of living: a 10-year follow-up of out-patients with schizophrenia. Acta Psychiatr Scand 1998; 98:3909 .
27. Huber G, Gross G, Schuttler R. A long-term follow-up study of schizophrenia: psychiatric course of illness and prognosis. Acta Psychiatr Scand 1975; 52:49-57.

28. Koivumaa-Honkanem HT, Viinamaki H, Honkanen R, Tanskanen A, Antikainen R, Niskanen L, et al. Correlates of life satisfaction among psychiatric patients. Acta Psychiatr Scand 1996; 94:372-8.

29. Osis MJ, Hard E, Faundes A, Alves G. Fatores associados à assistência pré-natal entre mulheres de baixa renda no Estado de São Paulo, Brasil. Rev Saúde Pública 1993; 27:49-53.

30. Barry MM, Crosby C. Quality of life as an evaluative measure in assessing the impact of community cares on people with long-term psychiatric disorders. Br J Psychiatry 1996; 168:210-6.

31. Skantze K, Malm U, Dencker SJ, May PRA, Corrigan P. Comparison of quality of life with standard of living in schizophrenic out-patients. Br J Psychiatry 1992; 161:797-801.

32. Browne S, Roe M, Lane A. Quality of life in schizophrenia: relationship to sociodemographic factors, symptomatology and tardive dyskinesia. Acta Psychiatr Scand 1996; 94:118-24.

33. Awad AG, Voruganti LNP. Intervention research in psychosis: issues related to the assessment of quality of life. Schizophr Bull 2000; 26:557-64.

34. Mercier C. Improving the quality of life of people with chronic mental disorders. Soc Indic Res 1994; 33:165-92.

35. Ruggeri M, Warner R, Bisoffi G, Fontecedro L. Subjective and objective dimensions of quality of life in psychiatric patients: a factor analytical approach. Br J Psychiatry 2001; 178:268-75.

36. Brow-Thomas CC, Velligan DI, Miller AL, Olsen J. Predicting quality of life from symptomatology in schizophrenia at exacerbation and stabilization. Psychiatry Res 1999; 86:131-42.

37. Voruganti L, Heslegrave R, Awad AG, Seeman MV. Quality of life measurement in schizophrenia: reconciling the quest for subjectivity with the question of reliability. Psychol Med 1998; 28:16572.

38. Lehman AF, Postrado LT, Rachoba LT. Convergent validation of quality of life assessment for persons with severe mental illness. Qual Life Res 1993; 2:327-33.

Submitted on 05/Apr/2004

Final version resubmitted on $01 /$ Oct/2004

Approved on 28/Oct/2004 